\title{
Optimal Tradable Credits Scheme and Congestion Pricing with the Efficiency Analysis to Congestion
}

\author{
$\mathrm{Ge} \mathrm{Gao}^{1}$ and Jun $\mathrm{Hu}^{1,2}$ \\ ${ }^{1}$ Institute of System Science, School of Traffic and Transportation, Beijing Jiaotong University, Beijing 100044, China \\ ${ }^{2}$ Faculty of Computer Science, Chengdu Normal University, Chengdu 611130, China \\ Correspondence should be addressed to Jun Hu; hujun@cdu.edu.cn
}

Received 27 May 2015; Accepted 29 June 2015

Academic Editor: Gabriella Bretti

Copyright (C) 2015 G. Gao and J. Hu. This is an open access article distributed under the Creative Commons Attribution License, which permits unrestricted use, distribution, and reproduction in any medium, provided the original work is properly cited.

\begin{abstract}
We allow for three traffic scenarios: the tradable credits scheme, congestion pricing, and no traffic measure. The utility functions of different modes (car, bus, and bicycle) are developed by considering the income's impact on travelers' behaviors. Their purpose is to analyze the demand distribution of different modes. A social optimization model is built aiming at maximizing the social welfare. The optimal tradable credits scheme (distribution of credits, credits charging, and the credit price), congestion pricing fees, bus frequency, and bus fare are obtained by solving the model. Mode choice behavior under the tradable credits scheme is also studied. Numerical examples are presented to demonstrate the model's availability and explore the effects of the three schemes on traffic system's performance. Results show congestion pricing would earn more social welfare than the other traffic measures. However, tradable credits scheme will give travelers more consumer surplus than congestion pricing. Travelers' consumer surplus with congestion pricing is the minimum, which injures the travelers' benefits. Tradable credits scheme is considered the best scenario by comparing the three scenarios' efficiency.
\end{abstract}

\section{Introduction}

Traffic congestion has become one of the most severe social problems in modern societies. It has attracted the largest share of attention from economists and engineers. Congestion pricing has been advocated to reduce traffic congestion since 1920. In order to maximize social welfare, Pigou [1] firstly argued that travelers have to pay a congestion toll to make up for the discrepancy between their average and marginal travel costs. As is well known, the major defect of congestion pricing is unfairness [2]. Given the general resistance to congestion charges, the market-based demand management instruments have gained increasing attention as more effective and cost-efficient solutions to the congestion problem [3]. Tradable credits scheme is one of the tools, which can be traced back to Dales [4] for the purpose of managing water quality. Tradable credit scheme can be described as a cap-and-trade scheme: the regulator determines the policy target (the cap) in terms of quantity (total number of permits or credits) and distributes the total number of permits or credits to all users, while a free trading market determines the price for these permits or credits [5]. In recent years, more and more researchers and planners have turned to study the tradable credits scheme owning to its equality and because it is revenue-neutral. Yang and Wang [6] explored the application of tradable credits in traffic networks. Wang et al. [5] considered heterogeneous users with discrete or continuous value of travel time in a tradable credits scheme. Nie [7] analyzed the effect of transaction costs on traveler behaviors. Wu et al. [3] developed a modeling framework that considered the effect of income on travelers' choices of trip generation, mode, and route on multimodal transportation networks. Bottleneck congestion under the tradable credits scheme was also analyzed $[8,9]$. He et al. [10] designed tradable credit schemes on networks with two types of players, Cournot-Nash $(\mathrm{CN})$ players and Wardropequilibrium (WE) players. Wang et al. [11] extended the tradable credits to continuous network design. Li and Gao [12] proposed a discrete bilevel programming model for managing rush hour congestion by using lane reversal and tradable credits. Bao et al. [13] analyzed traveler's behavior by considering loss aversion under the tradable credits scheme. 
Zhu et al. [14] explored the properties of the multiclass traffic network equilibria under a tradable credit scheme. Yet, few literatures compared with tradable credits scheme and congestion pricing from the angle of social welfare and consumer surplus.

In this paper, the utility functions of different modes (car, bus, and bicycle) under three scenarios (tradable credits scheme, congestion pricing, and no traffic measures) are developed by considering the income's impact on traveler behaviors. A social optimization model is built to maximize the social welfare. In the model, bus fares and frequencies, tradable credits scheme, and congestion pricing fees are determined by the planner in order to guide travelers' behaviors. Numerical examples are presented to demonstrate the model and explore the effects of the three schemes on social welfare and consumer surplus. By comparing the three scenarios' social welfare, consumer surplus, and bus fare, tradable credits scheme is considered to be the best scenario.

The paper is organized as follows. The utility functions and programming model are established in Section 2. Section 3 gives the numerical example to demonstrate the model's availability. Finally, Section 4 concludes the paper.

\section{Utility Functions and the Model}

2.1. The Tradable Credits Scheme. A tradable credit distribution and charging scheme is introduced as follows before proposing the models [6].

(1) Initial Distribution of Credits. Credits are distributed freely to all travelers. The total amount of credits is predetermined and the credits are month specific, so no one can benefit from banking or stocking credits for the future.

(2) Trip Distance Specific Credits Charges. Here, the credits that travelers hold can be used on any link but the amount of credit charging is trip distance specific. That is to say, the longer the trip distance, the less the credits to be charged.

(3) Trading Credits. Travelers' requirements for credits will generally differ from their travelling modes. A free market is supposed for credit trading for travelers to buy or sell credits according to their individual travel needs. The government does not interfere in the market as a buyer or seller but merely acts as a manager to monitor the system. Here, assume that the market is competitive; thus a uniform and constant credit price prevails. At the same time, we also assume that the transaction cost and administrative cost are both supposed to be zero and are ignored in this paper.

2.2. Utility Functions. We suppose in a linear city there is a road with a capacity of $Q$ vehicles/hour, where $Y$ commuters per kilometer and hour travel $l \mathrm{~km}$ in the same direction. There exist three modes: car, bus, and bicycle. All travel commuters choose one of the three modes, in a utility maximization framework. For the two motorized modes, we consider congestion externalities caused both by their interaction while in motion [15].
(1) Car User's Utility. For car users, under the tradable credits scheme, the utility contains the following parts: daily income, the preference of car, travelling time, the expenses of purchasing credits, and operating cost. Therefore, the expression can be written as follows:

$$
\begin{aligned}
U_{a}= & y+B_{a} \cdot \theta-\mathrm{SVT} \cdot T_{a} \cdot l-P \cdot\left(k_{n} \cdot l-k_{m}\right)-C_{a} \\
& \cdot l .
\end{aligned}
$$

Similarly, the utilities under congestion pricing and no traffic measures can be denoted by

$$
\begin{aligned}
& U_{a}=y+B_{a} \cdot \theta-\mathrm{SVT} \cdot T_{a} \cdot l-C_{a} \cdot l-p_{a} \cdot l, \\
& U_{a}=y+B_{a} \cdot \theta-\mathrm{SVT} \cdot T_{a} \cdot l-C_{a} \cdot l,
\end{aligned}
$$

where $y$ denotes the traveler's daily income. $B_{a}$ is the preference of car. $\theta$ is a parameter which is related to the preference. SVT is the value of time. $C_{a}$ is the car's operating cost per kilometer. $p_{a}$ is the charging fees per kilometer on the link. $l$ denotes the trip distance. $P$ is the credit price when the credits market is equilibrium. $k_{m}$ denotes the initial distribution of credits. $k_{n}$ is the number of credits to be charged per car per kilometer. $T_{a}$ is the travelling time per kilometer per car. It can be written as follows [15]:

$$
T_{a}=\alpha\left(\frac{(C / 100+1) f+l Y_{a}}{Q}\right)+\beta
$$

Here, $\alpha, \beta$ are the parameters. $C$ denotes bus load. $f$ is the bus frequency. $Y_{a}$ is the car demand per kilometer. $Q$ is the road capacity.

(2) Passenger's Utility. Under the tradable credits scheme, passenger's utility mainly contains daily income, the preference of bus, travelling time in vehicle, the boarding time, bus fare, and the reward by selling credits. It can be represented as follows:

$$
\begin{aligned}
U_{b}= & y+B_{b} \cdot \theta-\mathrm{SVT} \cdot T_{b} \cdot l-\frac{\mathrm{SVT} \cdot Y_{b} \cdot T_{w}}{f}-P_{b} \cdot l \\
& +P \cdot k_{m} .
\end{aligned}
$$

The utility of one passenger under congestion pricing can be denoted as follows:

$$
U_{b}=y+B_{b} \cdot \theta-\mathrm{SVT} \cdot T_{b} \cdot l-\frac{\mathrm{SVT} \cdot Y_{b} \cdot T_{w}}{f}-P_{b} \cdot l,
$$

where $B_{b}$ is the preference of bus. $T_{w}$ is the average boarding time. $P_{b}$ is the bus fare per kilometer. $T_{b}$ denotes bus's travelling time per kilometer, and it is equal to $T_{a}$.

Under no traffic measures, passenger has the same utility function with congestion pricing.

For bus company, it has operating cost. Here, bus company's operating cost can be written as follows:

$$
C_{b}=\left(c_{b 0}+c_{b 1} \cdot C\right) \cdot f \cdot\left(T_{b}+T_{w}\right),
$$

where $c_{b 0}$ denotes the fixed operating cost per bus and hour. $c_{b 1}$ is the variable operating cost per bus and hour. So the 
term in the left bracket represents operational cost per bus and hour.

(3) Bicyclist's Utility. Under the tradable credits scheme, the utility of the bicyclist is given by

$$
U_{c}=y-\mathrm{SVT} \cdot T_{c}+P \cdot k_{m} .
$$

In (7), the first term denotes the daily income; the second term represents bicyclist's travelling time; and the third term is the reward by selling credits. $T_{c}$ is the bicyclist's travelling time.

Under the scheme of congestion pricing and no traffic measures, bicyclist has the same utility. It can be represented as follows:

$$
U_{c}=y-\mathrm{SVT} \cdot T_{c} .
$$

Traffic flow will transfer among different modes. It will reach the mode equilibrium at last and three modes' utilities will be equal.

Under the tradable credits scheme, according to $U_{a}=U_{b}$, we have

$$
\theta^{a}=\frac{l \cdot\left(p \cdot k_{n}+C_{a}-p_{b}\right)-\left(\mathrm{SVT} \cdot Y_{b} \cdot T_{w}\right) / f}{B_{a}-B_{b}} .
$$

According to $U_{b}=U_{c}$, we have

$$
\theta^{b}=\frac{\operatorname{SVT} \cdot\left(T_{b} \cdot l+\left(Y_{b} \cdot T_{w}\right) / f-T_{c}\right)+p_{b} \cdot l}{B_{b}} .
$$

Under no traffic measure, $\theta^{a}$ and $\theta^{b}$ can be represented as follows:

$$
\begin{aligned}
& \theta^{a} \\
& =\frac{l \cdot\left(C_{a}-p_{b}\right)+\operatorname{SVT} \cdot\left(T_{a} \cdot l-\left(Y_{b} \cdot T_{w}\right) / f-T_{b} \cdot l\right)}{B_{a}-B_{b}}, \\
& \theta^{b}=\frac{\operatorname{SVT} \cdot\left(T_{b} \cdot l+\left(Y_{b} \cdot T_{w}\right) / f-T_{c}\right)+p_{b} \cdot l}{B_{b}} .
\end{aligned}
$$

Under the congestion pricing scheme, $\theta^{a}$ and $\theta^{b}$ are written as follows:

$$
\begin{aligned}
& \theta^{a} \\
& =\frac{l \cdot\left(C_{a}+p_{a}-p_{b}\right)+\operatorname{SVT} \cdot\left(T_{a} \cdot l-\left(Y_{b} \cdot T_{w}\right) / f-T_{b} \cdot l\right)}{B_{a}-B_{b}}, \\
& \theta^{b}=\frac{\operatorname{SVT} \cdot\left(T_{b} \cdot l+\left(Y_{b} \cdot T_{w}\right) / f-T_{c}\right)+p_{b} \cdot l}{B_{b}} .
\end{aligned}
$$

We can define a modal split where people with value of $\theta$ between 0 and $\theta^{b}$ choose cycling, people with value of $\theta$ between $\theta^{b}$ and $\theta^{a}$ choose bus, and the remainder choose car [16].

Thus, the number of people using each mode can be represented as follows:

$$
\begin{aligned}
& Y_{a}=Y \cdot\left(1-\theta^{a}\right), \\
& Y_{b}=Y \cdot\left(\theta^{a}-\theta^{b}\right), \\
& Y_{c}=Y-Y_{a}-Y_{b} .
\end{aligned}
$$

2.3. The Model. In urban traffic system, the social planner tries to minimize the system cost or maximize the social welfare by some traffic policy. In this paper, the social planner could maximize social welfare by tradable credits scheme or congestion pricing. According to the general theory of welfare economics, the social welfare is the sum of consumer and producer surpluses. Consumer surplus can be calculated by the following expression:

$$
\mathrm{CS}=Y \cdot\left(\int_{\theta^{a}}^{1} U_{a} d \theta+\int_{\theta^{b}}^{\theta^{a}} U_{b} d \theta+\int_{0}^{\theta^{b}} U_{c} d \theta\right),
$$

where $U_{a}, U_{b}$, and $U_{c}$ are given by aforementioned equations.

In this paper, producer surplus is equal to bus company revenues plus government revenues. Bus company revenues $\left(I_{b}\right)$ are equal to operating revenues minus operational transit costs:

$$
I_{b}=p_{b} \cdot Y_{b} \cdot l-C_{b}
$$

As is well known, government revenues are zero with tradable credits scheme (Yang and Wang). So the social welfare is given by

$$
\mathrm{SW}=\mathrm{CS}+p_{b} \cdot Y_{b} \cdot l-C_{b} .
$$

Under the congestion pricing scheme, the social welfare is given by

$$
\mathrm{SW}=\mathrm{CS}+p_{b} \cdot Y_{b} \cdot l-C_{b}+p_{a} \cdot Y_{a} \cdot l .
$$

On the right hand side of (17), the second term denotes the government revenues $\left(I_{g}\right)$ which stems from congestion pricing.

Under the tradable credits scheme, the credits used by drivers should not exceed the total credits:

$$
Y_{a} \cdot k_{n} \cdot l \leq K
$$

In order to realize self-financing, bus company's operating revenues should be equal to or greater than operational transit costs:

$$
p_{b} \cdot Y_{b} \cdot l \geq C_{b}
$$

There is also the constraint of minimal bus frequency, which ensures that all the passengers could be carried away:

$$
C \geq \frac{Y_{b} \cdot l}{f} .
$$

Based on the above analysis, considering the planner's purpose and travelers behaviors, programming can be formulated as follows:

$$
\begin{array}{ll}
\operatorname{Max} & \mathrm{SW}=\mathrm{CS}+I_{g}+I_{b} \\
\text { s.t } & Y_{a}+Y_{b} \leq Y \\
& Y_{a} \geq 0, Y_{b} \geq 0, Y_{c} \geq 0 \\
& \text { Equations (18)-(20). }
\end{array}
$$


TABLe 1: Parameter values used in numerical analysis.

\begin{tabular}{|c|c|c|c|}
\hline Parameter & Description & Value & Units \\
\hline$l$ & Trip distance & 12 & $\mathrm{~km}$ \\
\hline Inc & Daily income & 100 & $\mathrm{US} \$ / \mathrm{d}$ \\
\hline SVT & The value of time & 1 & $\mathrm{US} \$ / \mathrm{h}$ \\
\hline K & Total credits & 8000 & - \\
\hline$\alpha$ & Parameter of in-vehicle travel time & 0.08 & - \\
\hline$\beta$ & Parameter of in-vehicle travel time & 0.0125 & - \\
\hline$C_{a}$ & Car operational cost per kilometer & 0.3804 & US\$/car \\
\hline$B_{a}$ & Car modal constant & 30 & - \\
\hline$B_{b}$ & Bus modal constant & 15 & - \\
\hline$V_{c}$ & The average speed of bicycle & 20 & $\mathrm{~km} / \mathrm{h}$ \\
\hline$c_{b 0}$ & Fixed operational cost per bus per hour & 20.9930 & $\mathrm{US} \$ / \mathrm{h}$ \\
\hline$c_{b 1}$ & Variable operational cost unit of bus capacity per hour & 0.2095 & $\mathrm{US} \$ / \mathrm{h}$ \\
\hline Q & Road capacity & 5400 & veh/h \\
\hline$Y$ & Total demand per kilometer and hour & 900 & $\mathrm{pax} / \mathrm{km} \mathrm{h}$ \\
\hline
\end{tabular}

TABLE 2: Results of numerical simulations of scenarios.

\begin{tabular}{|c|c|c|c|}
\hline Parameter & $\begin{array}{c}\text { Tradable } \\
\text { credits }\end{array}$ & $\begin{array}{l}\text { Congestion } \\
\text { pricing }\end{array}$ & $\begin{array}{l}\text { No traffic } \\
\text { measures }\end{array}$ \\
\hline Car demand $Y_{a}(\mathrm{pax} / \mathrm{km})$ & 28 & 530 & 608 \\
\hline Bus demand $Y_{b}(\operatorname{pax} / \mathrm{km})$ & 827 & 321 & 267 \\
\hline Bicycle demand $Y_{c}(\mathrm{pax} / \mathrm{km})$ & 145 & 49 & 25 \\
\hline Bus fare $(\mathrm{US} \$ / \mathrm{km})$ & 0.18 & 0.39 & 0.42 \\
\hline Bus frequency (buses/h) & 99 & 37 & 32 \\
\hline Congestion pricing fee (US\$/km) & - & 0.18 & - \\
\hline Credits distribution $(-/ \mathrm{km})$ & 12.23 & - & - \\
\hline Credits charging $(-/ \mathrm{km})$ & 2.43 & - & - \\
\hline Credit price (US\$) & 0.2 & - & - \\
\hline Consumer surplus ( $\times 10^{5}$ US $\left.\$\right)$ & 8.83 & 8.25 & 8.43 \\
\hline Social welfare $\left(\times 10^{5}\right.$ US\$) & 8.83 & 9.025 & 8.43 \\
\hline
\end{tabular}

The above-mentioned programming describes the planner's decision-making. We can get the decision variables $f$, $k_{m}, k_{n}, p$, and $p_{a}\left(k_{m}\right.$ denotes the initial distribution of credits; $k_{n}$ is the number of credits to be charged per car per kilometer; $p$ is the credit price when the credits market is equilibrium; $p_{a}$ is the charging fees per kilometer on the link; $f$ is the bus frequency) by solving the model.

\section{Numerical Experiments}

All three scenarios are solved as optimization problems by using the software Matlab 2010b and Lingo 11. The input parameters are shown in Table 1 . Numerical results are presented in Table 2 and analyzed in detail below.

3.1. Tradable Credits Scheme versus No Measures. As shown in Table 2, tradable credits scheme will earn more social welfare and consumer surplus comparing to no traffic measures. It also changes the mode split greatly. Most drivers transfer to the bus and bicycle. This is because drivers must purchase extra credits if they want to satisfy their travelling demand. On the contrary, the bus passengers and cyclists could obtain the tangible reward by selling credits to car users. Travelers have higher preference to the bus. More drivers will transfer to bus than the bicycle. Accordingly, tradable credits scheme' bus frequency will be higher than no traffic measures. Compared with no traffic measures, tradable credits scheme has lower bus fare. The reason is that more passengers ensure that lower bus fare satisfies bus system's self-financing. Under the optimal tradable credits scheme, the optimal credit price is $0.2 \$ / \mathrm{km}$, the credits charging is $2.43 / \mathrm{km}$, and the distribution of credits is 12.23 /person. By considering the social welfare, consumer surplus, and bus fare, tradable credits scheme is better than no traffic measures.

3.2. Tradable Credits Scheme versus Congestion Pricing. We can see from Table 2 that congestion pricing will earn more social welfare than the tradable credits scheme. The reason is that the government could earn revenue by congestion pricing, but it is revenue-neutral under the tradable credits scheme. A look at Table 2, comparing tradable credits scheme and congestion pricing, shows that the tradable credits scheme is a policy that works in which it increases the total consumer surplus. This is because, under the tradable credits scheme, the bus passengers and cyclists could earn pay by selling credits, but they earn no benefits under the congestion pricing scheme. Based on the same reason, more people will transfer to buses and bicycles under the tradable credits scheme (see Table 2). We can see from Table 2 that the tradable credits scheme's bus fare is lower than the congestion pricing. This is because tradable credits scheme has more bus passengers than congestion pricing.

3.3. Interesting Findings in This Example. Some interesting trends in this example are also found. Now we illustrate them as follows.

As shown in Figure 1, the greater the number of bus passengers, the more the reduction in the bus fare. The 


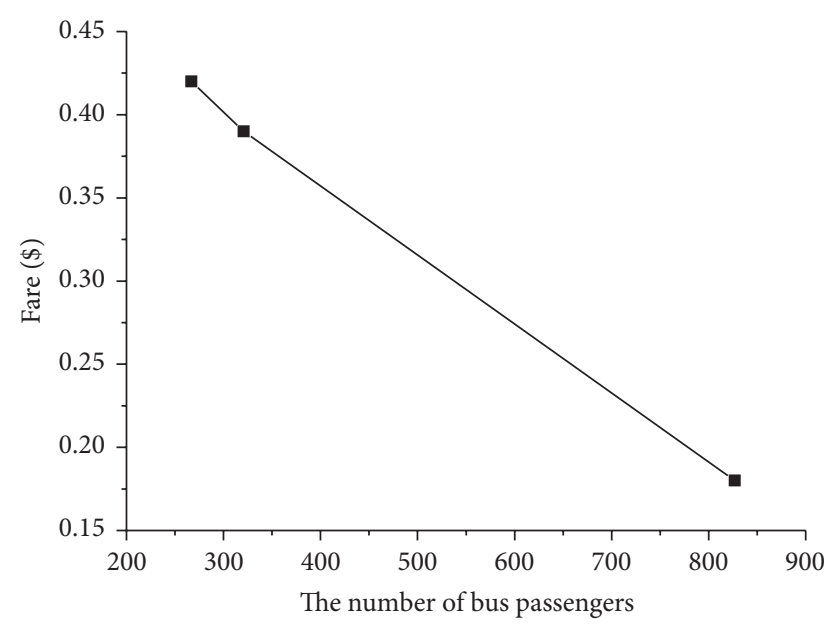

FIgURE 1: The effect of the number of bus passengers on the fares.

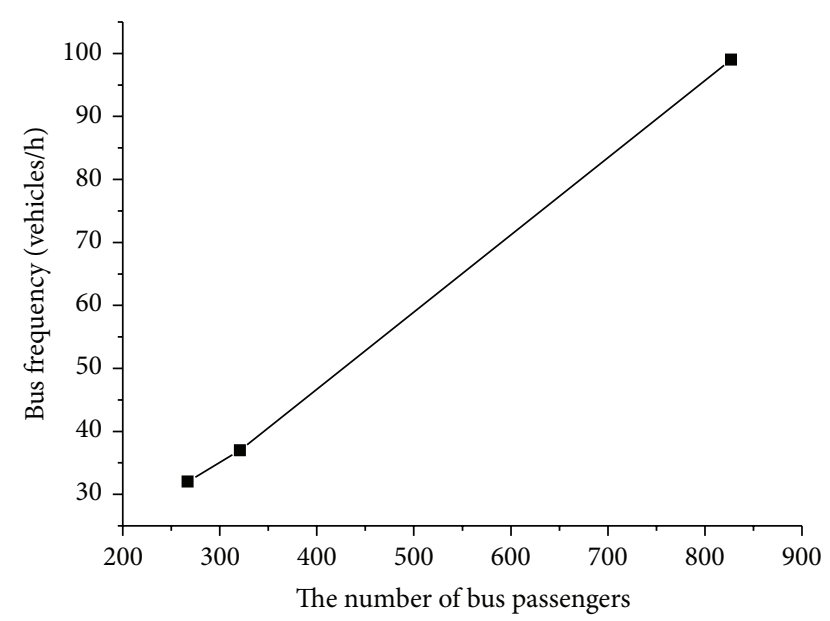

FIGURE 2: The effect of the number of bus passengers on the bus frequency.

process can be properly explained. More passengers ensure the buses are full loaded. That would mean lower fare could satisfy the bus system's self-financing. As expected, Figure 2 reveals that more passengers need more bus frequencies.

Based on the above analysis, although congestion pricing has the maximum social welfare, tradable credits scheme has more consumer surplus and lower bus fare. Therefore, by comparison, tradable credits scheme is the best scheme among the three scenarios.

\section{Conclusion}

The utility functions of different modes (car, bus, and bicycle) are developed in this paper by considering the income's impact on traveler behaviors. The demand distribution of different modes is analyzed. The consumer surplus and social welfare model were formulated. By solving the model, the optimal tradable credits scheme (the amount of distributed credits, the amount of credits charging, and the credit price), congestion pricing, bus's optimal frequency, and fare are obtained. This provides a reference for the planner. Numerical examples are presented to demonstrate the model's availability and explore the effects of the three schemes on social welfare and consumer surplus. Results show that congestion pricing would earn more social welfare than the other traffic measures. However, tradable credits scheme will give travelers more consumer surplus than congestion pricing. Travelers' consumer surplus is the minimum under the congestion pricing, which injures the travelers' benefits. Therefore, considering the social welfare, consumer surplus, and the bus fare, the tradable credits scheme is the best scenario.

\section{Conflict of Interests}

The authors declare that there is no conflict of interests regarding the publication of this paper.

\section{Acknowledgments}

This research is supported by the National Natural Science Foundation of China (Grant no. 61304187), China Postdoctoral Science Foundation (Grant no. 2014M560040), National Basic Research Program of China (T14JB00140), the Scientific Research Fund of Sichuan Provincial Education Department of China (Grant no. 15TD0038), the Scientific Research Fund of Sichuan Provincial Science and Technology Department of China (Grant no. 2014JY0111, Grant no. 2015GZ0333), and Chengdu Normal University of China (Grant no. CS14CX01, Grant no. CS14ZB01).

\section{References}

[1] A. C. Pigou, The Economics of Welfare, Macmillan, London, UK, 1st edition, 1920

[2] B. D. Taylor and R. Kalauskas, "Addressing equity in political debates over road pricing," Transportation Research Record, vol. 2187, pp. 44-52, 2010.

[3] D. Wu, Y. Yin, S. Lawphongpanich, and H. Yang, "Design of more equitable congestion pricing and tradable credit schemes for multimodal transportation networks," Transportation Research Part B: Methodological, vol. 46, no. 9, pp. 12731287, 2012.

[4] J. H. Dales, Pollution, Property, and Prices, University of Toronto Press, Toronto, Canada, 1968.

[5] X. Wang, H. Yang, D. Zhu, and C. M. Li, "Tradable travel credits for congestion management with heterogeneous users," Transportation Research Part E: Logistics and Transportation Review, vol. 48, no. 2, pp. 426-437, 2012.

[6] H. Yang and X. L. Wang, "Managing network mobility with tradable credits," Transportation Research Part B: Methodological, vol. 45, no. 3, pp. 580-594, 2011.

[7] Y. M. Nie, "Transaction costs and tradable mobility credits," Transportation Research Part B: Methodological, vol. 46, no. 1, pp. 189-203, 2012.

[8] F. Xiao, Z. Qian, and H. M. Zhang, "Managing bottleneck congestion with tradable credits," Transportation Research Part B: Methodological, vol. 56, pp. 1-14, 2013.

[9] L.-J. Tian, H. Yang, and H.-J. Huang, "Tradable credit schemes for managing bottleneck congestion and modal split with 
heterogeneous users," Transportation Research Part E: Logistics and Transportation Review, vol. 54, pp. 1-13, 2013.

[10] F. He, Y. Yin, N. Shirmohammadi, and Y. M. Nie, "Tradable credit schemes on networks with mixed equilibrium behaviors," Transportation Research Part B: Methodological, vol. 57, pp. 4765, 2013.

[11] G. M. Wang, Z. Y. Gao, M. Xu, and H. J. Sun, "Models and a relaxation algorithm for continuous network design problem with a tradable credit scheme and equity constraints," Computers and Operations Research, vol. 41, no. 1, pp. 252-261, 2014.

[12] Q. Li and Z. Gao, "Managing rush hour congestion with lane reversal and tradable credits," Mathematical Problems in Engineering, vol. 2014, Article ID 132936, 5 pages, 2014.

[13] Y. Bao, Z. Gao, M. Xu, and H. Yang, "Tradable credit scheme for mobility management considering travelers' loss aversion," Transportation Research Part E: Logistics and Transportation Review, vol. 68, pp. 138-154, 2014.

[14] D. L. Zhu, H. Yang, C. M. Li, and X. L. Wang, "Properties of the multiclass traffic network equilibria under a tradable credit scheme," Transportation Science, vol. 49, no. 3, pp. 519-534, 2014.

[15] L. J. Basso, C. A. Guevara, A. Gschwender, and M. Fuster, "Congestion pricing, transit subsidies and dedicated bus lanes: efficient and practical solutions to congestion," Transport Policy, vol. 18, no. 5, pp. 676-684, 2011.

[16] L. J. Basso and A. Zhang, "Sequential peak-load pricing: the case of airports and airlines," Canadian Journal of Economics, vol. 41, no. 3, pp. 1087-1119, 2008. 


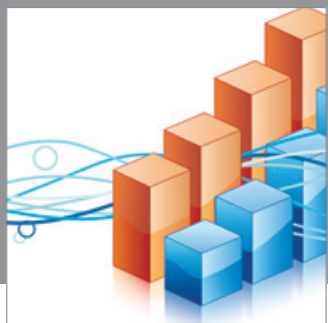

Advances in

Operations Research

mansans

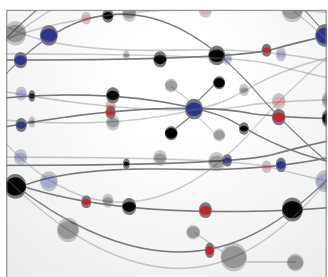

The Scientific World Journal
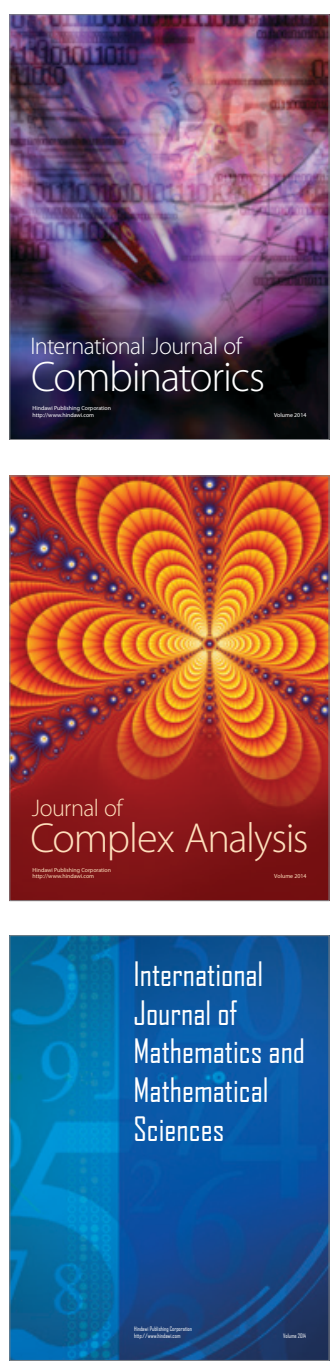
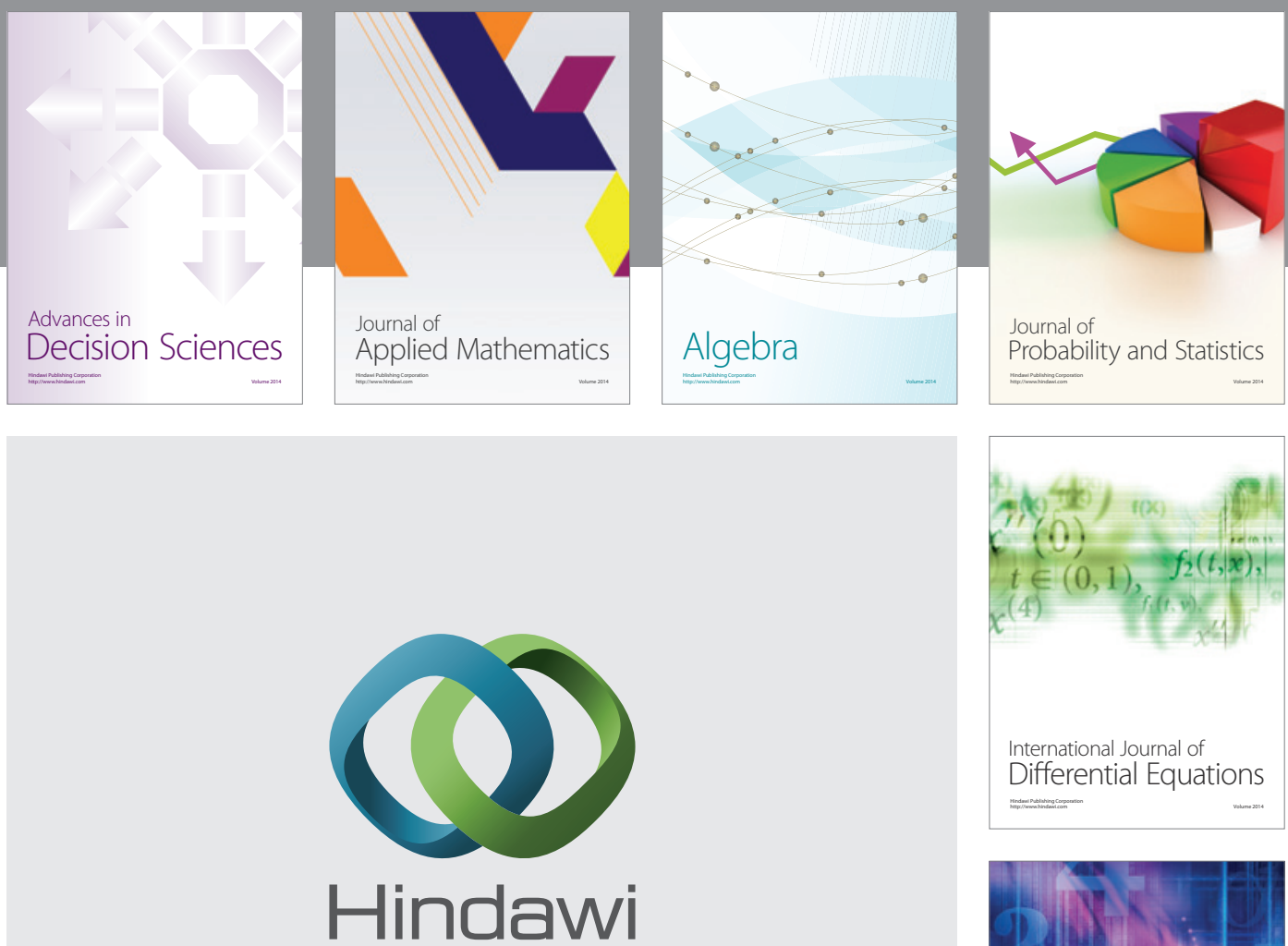

Submit your manuscripts at http://www.hindawi.com
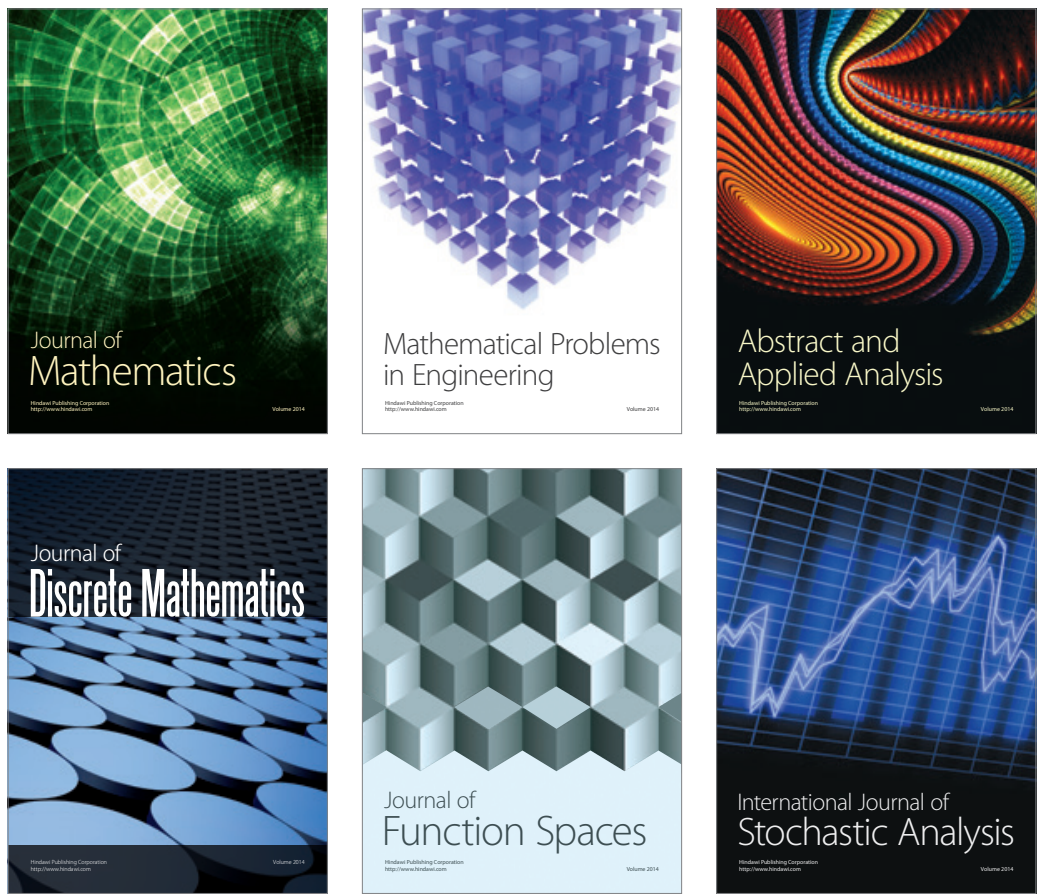

Journal of

Function Spaces

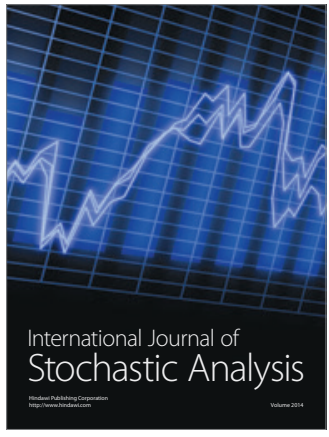

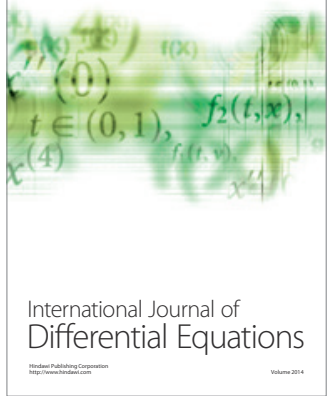
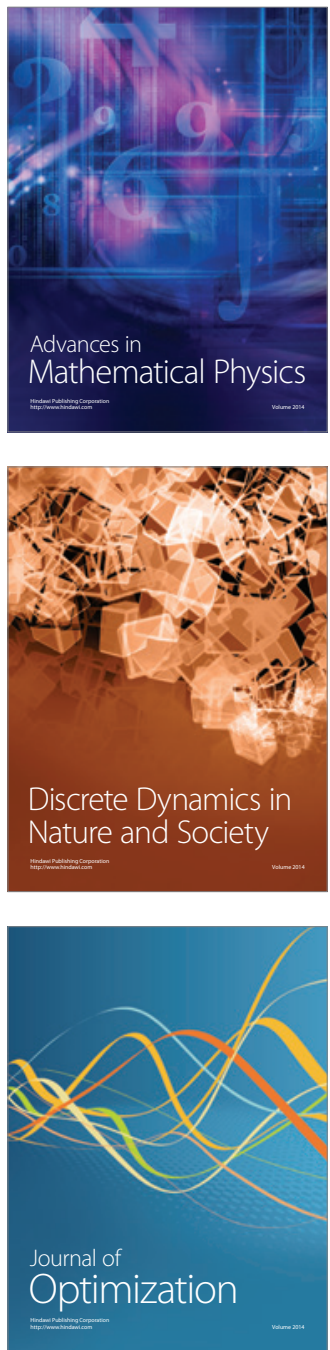